\title{
Structural characteristics of the institutional environment for young children
}

\author{
Rifkat J. Muhamedrahimov ${ }^{a}$, Irina A. Arintcina ${ }^{a}$, Maria Y. Solodunova ${ }^{a}$, \\ Varvara O. Anikina ${ }^{a}$, Marina J. Vasilyeva ${ }^{a}$, Daria I. Chernego ${ }^{a}$, \\ Larissa A. Tsvetkova ${ }^{a}$, Elena L. Grigorenko ${ }^{\mathrm{a}, \mathrm{b}}$ \\ a Laboratory of Translational Science of Early Childhood, St. Petersburg State University, \\ St. Petersburg, Russian Federation \\ ${ }^{\mathrm{b}}$ Child Study Center, Yale University, USA \\ ${ }^{\star}$ Corresponding author. E-mail: rjm@list.ru
}

The research literature suggests that institutions for children left without parental care do not provide environments that adequately promote children's development, and that characteristics of orphanages should be considered as an environmental factor influencing developmental difficulties in children living in institutions and later in post-institutional families. This study aimed to analyze the structural characteristics of the caregiving environment in two St. Petersburg (RF) orphanages-baby homes for children from birth to 4-5 years of age ( $\mathrm{BH} \mathrm{A}$ and $\mathrm{BH} \mathrm{B}$ ), and the maintenance of the structural interventions that were implemented in BH A during 2000-05 (The St. Petersburg-USA Orphanage Research Team, 2008). Both institutions belong to the Ministry of Health and are managed under the same medical regulations, providing about the same quality of medical care and nutrition. The results of the study show that the number of children living in each ward ( 4 to 6 in $\mathrm{BH} \mathrm{A}$ and 5 to 8 in $\mathrm{BH} \mathrm{B}$ ), and the child-caregiver ratio (2 to 3 for $\mathrm{BH} \mathrm{A}$ and 2.5 to 4 for $\mathrm{BH} \mathrm{B}$ ) in the two baby homes are about the same, while BH A have fewer staff members who are assigned to the ward (6-8 vs. 9-14 in BH B). The ward assistant teachers in BH A are assigned as the primary caregivers, working 5 days a week (39 hrs) vs. about 25 hrs a week for assistant teachers in BH B. While living in the baby home, children in $\mathrm{BH}$ A are integrated by age and disability (vs. segregation by age and partial disability integration in $\mathrm{BH}$ B), and are assigned to one ward (meaning the same caregivers, peers, rooms, etc.), while in $\mathrm{BH} \mathrm{B}$ the children change their ward when they reach a certain age or developmental milestone (number of wards children experienced $M(S D)=1.1(0.2)$ in BH A and $2.7(1.1)$ in $\mathrm{BH}$ B). Our results support the hypothesis that the structural characteristics of institutional environment in the two baby homes are different, and that in comparison with $\mathrm{BH} \mathrm{B}$, the structural characteristics of $\mathrm{BH} \mathrm{A}$ show more caregiving stability and consistency. The results also show that the interventions implemented in BH A within the St. Petersburg-USA Orphanage Research Project were maintained for many years after the project was finished. The specific features of 
an institutional caregiving environment should be taken into consideration in studies of the mental health and bio-behavioral development of children in institutions and postinstitutional families.

Keywords: institutions, children, caregiving environment, stability, consistency

\section{Introduction}

The research literature suggests that institutions for children left without parental care do not provide environments that adequately promote children's development (McCall et al., 2011; Rutter et al., 2010; The St. Petersburg-USA Orphanage Research Team, 2008; van IJzendoorn et al., 2011; Zeanah et al., 2009). Structural deficiencies of institutional environments are characterized by large numbers of children per ward (from 9 to $16+$ ), high child-caregiver ratios (6-8+), the practice of dividing children into groups (either by age or by disability status) and frequent transitions to new wards (Bakermans-Kranenburg et al., 2012). Often the quality of caregiving in these institutions is extremely low: Caregiver-child interactions are infrequent, limited to routine caretaking activities, delayed, and caregiver-directed rather than responsive to children's actions, and are conducted in an impersonal manner (Groark et al., 2013; Muhamedrahimov, 2000). In a study of orphans in the Greek Metera Babies Center (Vorria et al., 2003), infants spent 17.5 hours in bed, indicating that for a major part of the day they had little opportunity to interact with a caregiver. Observations of caregivers with children from birth to 3 months and 3 to 10 months of age once a week from 9:30 am to 12:30 pm-including routine caregiving and "free time"-over a 2-month period documented the minimum amount of caregiver-child interactions in one St. Petersburg (Russian Federation) orphanage for infants (Muhamedrahimov, 2000). Across these two age groups, caregivers initiated interactions with the children approximately $10 \%$ of the total available time (approximately $18 \mathrm{~min}$ from 9:30 am to 12:30 pm). They responded to children's initiations of social interaction less than $1 \%$ of the time (less than $2 \mathrm{~min}$ ); children cried for approximately $11 \mathrm{~min}$ before a caregiver responded; there was essentially no talking during more than half the time the caregivers were engaged in routine caregiving; and on average an individual child interacted with a caregiver for any reason for only approximately $12.4 \mathrm{~min}$ during any $3-\mathrm{hr}$. period and nearly half of this was associated with feeding. The social-emotional environment of infants and young children in these orphanages was characterized by severe deficits in the sensitivity, responsivity, and stability of the caregiving environment, as well as the neglect and maltreatment of the children.

Overall, institutions can be differentiated according to the severity of deprivation. Certain institutions can be categorized as "globally depriving institutions" that do not provide children with adequate medical care, nutrition, or sanitation (Gunnar, 2001). Psycho-social conditions in such institutions are very poor, since children spend most of the time in their cribs, do not have enough stimulation, and one-to-one interaction with caregivers is very rare. In "social-emotionally depriving institutions," children have adequate medical care and nutrition, but caregivers are business-like when performing routine caretaking activities and do not provide much interaction with children (Gunnar, 2001; The St. Petersburg-USA 
Orphanage Research Team, 2008). According to the results of the quasi-experimental intervention study, the structural characteristics of institutions for infants and young children was shown to be critical for the positive development of children in orphanages. Specifically, the double intervention program was designed to provide structural changes (by assigning two primary caregivers to smaller ageand disability-integrated groups, terminating transitions of children to new wards, and establishing a "Family Hour" for primary caregivers to be with their children), coupled with staff training (emphasizing sensitive and responsive caregiver-child interactions); it showed better developmental outcomes for children as compared with the intervention program implementing staff training only (Muhamedrahimov et al., 2004; The St. Petersburg-USA Orphanage Research Team, 2008).

A considerable number of studies have shown that children reared in institutions are at substantial risk in various domains of functioning, including their physical, cognitive, and general behavioral development (Bakermans-Kranenburg et al., 2012; The St. Petersburg-USA Orphanage Research Team, 2008; van Ijzendoorn et al., 2011). Those with a substantial history of institutional care (IC) ( 1-2 years) display a variety of long-term neurological, physical, cognitive, behavioral, and social-emotional difficulties (Nelson et al., 2011; Rutter et al., 2010). These adverse developmental outcomes in institutionalized children might be produced by other confounding risk factors, such as genetic or prenatal conditions, birth complications, or negative pre-orphanage experiences (Bakermans-Kranenburg et al., 2012; van Ijzendoorn et al., 2011). The literature cited above suggests that characteristics of institutions should be considered as an environmental factor influencing developmental difficulties in children living in institutions and later in post-institutional families. The aim of this work was to study the caregiving environments in St. Petersburg orphanages for infants and young children, including in the orphanage in which the intervention program (structural changes coupled with staff training) was implemented during 2000-05 (The St. Petersburg-USA Orphanage Research Team, 2008). The differences in the structural characteristics of these orphanages will be analyzed. It was assumed that the structural interventions implemented in one of the orphanages by the St. Petersburg-USA Orphanage Research Project were maintained by the orphanage personnel for many years after the project was finished, and that even those orphanages that belong to the same system of institutions would be different in their structural characteristics, namely in the stability and consistency of the institutional environment.

\section{Method}

\section{Participants}

Baby Homes. Two institutions (baby homes, BH) located in St. Petersburg, Russian Federation, for children approximately 0 to $4-5$ years of age left without parental care, participated in this study. These institutions are administered by the Russian Federation Ministry of Health and the local district administration, and were selected because their directors (head pediatricians) were willing to participate in the study, and they were relatively good institutions, providing adequate medical care and nutrition. Children arrive at the $\mathrm{BH}$ at various ages, but mostly in the first few months of life, either directly from the hospital where they were born or another 
hospital, or after spending a few months with their birth families. They were relinquished by their biological parents for a variety of reasons, including financial and behavioral inability to rear the child. Caregivers in the $\mathrm{BH}$ are all females with some training in health and education (The St. Petersburg-USA Orphanage Research Team, 2008).

In the first baby home (BH A), caregivers were trained in an intervention program by the St. Petersburg-USA Orphanage Research Project during 2000-05 (The St. Petersburg-USA Orphanage Research Team, 2008) to engage in sensitive and responsive interactions with children. Structural changes were also implemented in the institution, including a reduction in group size, the assignment of permanent primary caregivers to each group, age and disability integration of children, and no transitions of children to new wards. The second baby home $(\mathrm{BH} B)$ offers the same quality of medical care and nutrition for children as $\mathrm{BH} \mathrm{A}$, but for the staff and children of $\mathrm{BH} \mathrm{B}$ the research project was a new experience; no intervention was provided and $\mathrm{BH} \mathrm{B}$ had not been part of the St. Petersburg Orphanage Research Project.

Children. Environmental characteristics of the group of 119 children aged from birth to 5 years from the two baby homes ( 60 from $\mathrm{BH}$ A and 59 from $\mathrm{BH}$ B) were taken into consideration in the analysis of the general structural characteristics of each institutional environment. A group of 69 institutionalized children participated in the study of the number of wards and transitions that the children had experienced. Thirty-eight of them were from BH A (63.3\% of the total number of 60 children at that baby home) and 3 from BH B (52.5\% of the total number of 59 children in $\mathrm{BH} \mathrm{B}$ at the beginning of the study). The children's ages ranged from 5 to 60 months $[M(S D)=26.8(15.2)]$, including 5 aged 60 months $[M(S D)=30.9(16.6)]$ in $\mathrm{BH} A$ and 5 aged 46 months $[M(S D)=21.8(11.7)]$ in $\mathrm{BH} \mathrm{B}$. In the total sample there were 38 boys and 31 girls (19/19 in BH A and 19/12 in BH B). Based on the baby homes' medical records, out of the total group of 69 children, 30 were characterized as typically developing (TD) (18 from BH A and 12 from BH B) and 39 were children with a special needs (SN) (20 and 19, respectively). Descriptive data for the different groups and subgroups of children from the two baby homes are presented in Table 1.

Table 1. Descriptive data on children from the two baby homes

\begin{tabular}{|c|c|c|c|c|c|c|c|c|c|}
\hline \multirow{2}{*}{$\begin{array}{l}\text { Groups and } \\
\text { Subgroups }\end{array}$} & \multicolumn{3}{|c|}{ BH A } & \multicolumn{3}{|c|}{ BH B } & \multicolumn{3}{|c|}{ BHs A \& B } \\
\hline & TD & $\mathrm{SN}$ & Total & TD & SN & Total & TD & SN & Total \\
\hline $\mathrm{N}$ & 18 & 20 & 38 & 12 & 19 & 31 & 30 & 39 & 69 \\
\hline $\begin{array}{l}\text { Age range, } \\
\text { months }\end{array}$ & $5-57$ & $8-60$ & $5-60$ & $6-34$ & $5-46$ & $5-46$ & $5-57$ & $5-60$ & $5-60$ \\
\hline $\begin{array}{l}\text { Age } M(S D) \text {, } \\
\text { months }\end{array}$ & $\begin{array}{c}26.1 \\
(14.9)\end{array}$ & $\begin{array}{c}35.3 \\
(17.1)\end{array}$ & $\begin{array}{c}30.9 \\
(16.6)\end{array}$ & $\begin{array}{c}19.4 \\
(10.1)\end{array}$ & $\begin{array}{c}23.3 \\
(12.7)\end{array}$ & $\begin{array}{c}21.8 \\
(11.7)\end{array}$ & $\begin{array}{c}23.4 \\
(13.4)\end{array}$ & $\begin{array}{c}29.4 \\
(16.1)\end{array}$ & $\begin{array}{c}26.8 \\
(15.2)\end{array}$ \\
\hline $\begin{array}{l}\text { Gender, n } \\
\text { (boys/girls) }\end{array}$ & $7 / 11$ & $12 / 8$ & $19 / 19$ & $9 / 3$ & $10 / 9$ & $19 / 12$ & $16 / 14$ & $22 / 17$ & $38 / 31$ \\
\hline
\end{tabular}

Note: TD - typically developing children; SN - children with a special needs 


\section{Assessments}

Several structural components of the baby home environment were assessed to demonstrate differences in the caregiving stability/consistency for the children. Evaluation of the structural characteristics of the caregiving environment included the number of children in each baby home, the number of groups, group size, number of staff members working in the groups (assistant teachers, medical nurses, and nursery nurses), and an assignment of primary caregivers to each group, an implementation of age and disability integration of children in groups in contrast to the frequent transitioning of children between groups.

Assessment of transitions. A common practice in institutions is to have wards containing children of approximately the same age (e.g., infants, toddlers). Children are transitioned to older groups with new caregivers and older peers when they reach a certain age or developmental milestone (e.g., crawling, walking). In cases of infection, children also might be transferred for some period of time from the ward to a special medical treatment department at the baby home (the "isolation ward") and/or from the baby home to a children's hospital and back.

Procedure. In order to participate in the research project, an Institutional Agreement between each of the baby homes and St. Petersburg State University was drawn up and approved by both administrations. The baby home records were used to understand the staff employment and working schedules, as well as caregiver and children assignments. The project systematized the recording process by creating a set of checklists, which were tested, optimized, and implemented, and the data collection process was established.

Information about the structural characteristics of the baby home environment was extracted from official baby home documents, including employment and records on distribution of caregivers and children to groups for the period of September-December, 2014. Data on children's age and disability status were based on the baby home's medical records. The group records were used to determine whether children with different ages and disabilities were assigned to a group. The baby home kept records of children's transitions to new wards, from wards to the isolation ward, and to hospitals and back. These records were used to calculate the number of transitions each child had experienced before the research project started. The project systematized the recording process by creating a checklist of transitions to be filled in for each child by the baby home pediatricians.

\section{Results}

General information on structural characteristics of each institutional environment. At the beginning of the study, BH B housed 59 and BH A housed 60 children from birth to 5 years of age, placed into 8 and 12 wards, respectively (see Table 2). The number of wards in BH B included the isolation medical ward which was also used for long-term housing, while the isolation ward in $\mathrm{BH}$ A was used for the shortterm observation of newly arrived children and the treatment of sick children. For the period of observation (September-December 2014), the number of children living in each ward (group size) varied from 5 to 8 in $\mathrm{BH} \mathrm{B}$ and from 4 to 6 in $\mathrm{BH}$ A. Children in $\mathrm{BH}$ B were assigned to different wards according to age; children 
with severe disabilities lived for long periods of time in the isolation medical ward (children 0 to 5 years of age) and/or in the special ward for disabled children (from 1 to 5 years of age). At BH B, there are two wards for children aged 0 to 7 months, one for children aged 7 to 18 months, one for children aged 1.5 to 2.5 years, and two for children aged 2.5 to 4 years; there is no age integration. The last ward included typically developing children and children with disabilities. Children in BH B are transitioned to other wards with new caregivers and older peers when they reach a certain age or developmental milestone. All groups in $\mathrm{BH}$ A are integrated by age and disability and there are practically no transitions from one ward to another.

Routine care in both baby homes is provided by caregivers who work on the wards with the children. In both baby homes this includes medical nurses (MN) who work a 24-hr shift once every 4 days (4-5 MN per ward, 1 per shift; and in the $\mathrm{BH}$ B isolation medical ward there are $10 \mathrm{MN}, 2$ per shift), as well as assistant teachers. In BH B assistant teachers (AT) (3-4 per ward, 2 during the day with one working from 8 a.m. to 2 p.m. and the other from 2 p.m. to 8 p.m.) work in a shift for about $25 \mathrm{hrs}$ a week; there are no ATs in the BH B isolation ward.

In each of the BH A wards, 2 ATs are assigned as primary caregivers (plus $1 \mathrm{AT}$ in case of substitutions) working 5 days a week for $39 \mathrm{hrs}$ a week ( 2 days for $7 \mathrm{hrs}$ a day from 7:30 a.m. to 2:30 p.m., 2 days for 6 hrs a day from 2:30 p.m. to 8:30 p.m., and 1 day for $13 \mathrm{hrs}$ from 7:30 a.m. to 8:30 p.m.). The nursery nurses are assigned to each group in $\mathrm{BH} \mathrm{B}$ (2-5 per group, 1 during the day), while this position was eliminated in BH A. Depending on the group, the total number of caregivers who work with the children in each of the wards varies from 9 to 14 (4 during the day) in $\mathrm{BH} \mathrm{B}$, and from 6 to 8 ( 3 during the day) in $\mathrm{BH}$ A (see Table 2). Even when two caregivers are working on the ward, the child-caregiver ratio varies depending on the group, from 2.5 to 4 for $\mathrm{BH} \mathrm{B}$, and from 2 to 3 for $\mathrm{BH} \mathrm{A}$.

Table 2. Structural characteristics of institutional environment in two baby homes

\begin{tabular}{|c|c|c|c|}
\hline \multicolumn{2}{|c|}{ Baby Home Characteristics } & \multirow{2}{*}{$\begin{array}{c}\text { BH A } \\
60\end{array}$} & \multirow{2}{*}{$\begin{array}{c}\text { BH B } \\
59\end{array}$} \\
\hline Number of children & & & \\
\hline Number of wards & & 12 & 8 \\
\hline Ward size & & $4-6$ & $5-8$ \\
\hline \multirow{4}{*}{$\begin{array}{l}\text { Number of } \\
\text { staff members } \\
\text { per ward } \\
\text { (total / during the day) }\end{array}$} & assistant teachers & $3-4 / 2$ & $2-3 / 2$ \\
\hline & medical nurses & $4-5 / 1$ & $4-5 / 1$ \\
\hline & nursery nurses & $2-5 / 1$ & No \\
\hline & total staff in ward & $9-14 / 4$ & $6-8 / 3$ \\
\hline \multicolumn{2}{|c|}{ Primary caregivers assigned } & Yes & No \\
\hline \multicolumn{2}{|l|}{ Age integration } & Yes & No \\
\hline \multicolumn{2}{|l|}{ Disability integration } & Yes & Partly \\
\hline \multicolumn{2}{|l|}{ Transition to new wards } & No & Yes \\
\hline
\end{tabular}

Number of wards the children experienced. Comparisons revealed a significant difference in the number of wards to which children were assigned in $\mathrm{BH} \mathrm{A}$ and in BH B for the total number of children $\left[\chi^{2}(4, N=69)=45.2, p<.001\right]$, and for all subgroups: for typically developing children (TD) $\left[\chi^{2}(3, N=30)=19.4, p<.001\right]$, 
and for children with special needs $(\mathrm{SN})\left[\chi^{2}(4, N=39)=25.6, p<.001\right]$ (see Table $3)$. Our results show that children in $\mathrm{BH} \mathrm{B}$ were assigned to a greater number of wards [for different subgroups, number of wards $M(S D)=2.6(1.0)$ to $2.8(1.1)$ ] than children in $\mathrm{BH} \mathrm{A}[M(S D)=1.1(0.2)]$.

Number of transitions the children experienced. Comparisons of the number of transitions children had experienced (including from one ward to another, from a ward to the isolation ward, from the baby home to a children's hospital and back) revealed a differentiation between $\mathrm{BH} \mathrm{A}$ and $\mathrm{BH}$ B for the total group $[M(S D)=3.9$ (3.0) in BH B and 3.2 (3.5) in BH A; $\left.\chi^{2}(10, N=69)=16.0, p=.099\right]$, mostly because of differences for typical children (TD) $[M(S D)=2.7(1.4)$ in $\mathrm{BH}$ B and 1.4 (1.5) in $\mathrm{BH} \mathrm{A} ; \chi^{2}(5, N=30)=10.7, p=.058$; Mann-Whitney $\left.\mathrm{U}=58, p=.035\right]$, but no statistical differences for children with special needs (see Table 3 ).

Table 3. Number of wards and transitions in two baby homes

\begin{tabular}{|c|c|c|c|c|c|c|}
\hline \multirow[t]{2}{*}{ Groups } & \multicolumn{2}{|c|}{$\begin{array}{c}\text { N of Wards } \\
M(S D) \\
\text { (Min-Max) }\end{array}$} & \multirow[t]{2}{*}{$\begin{array}{c}\chi^{2} \\
(\mathrm{df}, \mathrm{N})\end{array}$} & \multicolumn{2}{|c|}{$\begin{array}{c}\text { N of Transitions } \\
M(S D) \\
(M i n-M a x)\end{array}$} & \multirow[t]{2}{*}{$\begin{array}{c}\chi^{2} \\
(\mathbf{d f}, \mathbf{N})\end{array}$} \\
\hline & BH A & BH B & & BH A & BH B & \\
\hline $\mathrm{TD}$ & $\begin{array}{c}1.1(0.2) \\
\quad(1-2)\end{array}$ & $\begin{array}{c}2.6(1.0) \\
\quad(1-4)\end{array}$ & $\begin{array}{l}19.4^{* * *} \\
(3,30)\end{array}$ & $\begin{array}{c}1.4(1.5) \\
(0-5)\end{array}$ & $\begin{array}{l}2.7(1.4) \\
\quad(0-4)\end{array}$ & $\begin{array}{c}10.7^{+} \\
(5,30)\end{array}$ \\
\hline $\mathrm{SN}$ & $\begin{array}{c}1.1(0.2) \\
\quad(1-2)\end{array}$ & $\begin{array}{l}2.8(1.1) \\
\quad(1-5)\end{array}$ & $\begin{array}{l}25.6^{* * *} \\
(4,39)\end{array}$ & $\begin{array}{c}4.8(4.1) \\
(0-15)\end{array}$ & $\begin{array}{c}4.7(3.5) \\
(0-14)\end{array}$ & $\begin{array}{c}12.1 \\
(10,39)\end{array}$ \\
\hline Total & $\begin{array}{c}1.1(0.2) \\
(1-2)\end{array}$ & $\begin{array}{c}2.7(1.1) \\
(1-5)\end{array}$ & $\begin{array}{l}45.2^{* * *} \\
(4,69)\end{array}$ & $\begin{array}{c}3.2(3.5) \\
(0-15)\end{array}$ & $\begin{array}{c}3.9(3.0) \\
(0-14)\end{array}$ & $\begin{array}{c}16.0^{+} \\
(10,69)\end{array}$ \\
\hline
\end{tabular}

${ }^{+}-p<.10 ;{ }^{* *}-p<.001$

\section{Discussion}

The research literature suggests that institutions for children left without parental care do not provide environments that adequately promote children's development (McCall et al., 2011; Rutter et al., 2010; The St. Petersburg-USA Orphanage Research Team, 2008; van IJzendoorn et al., 2011; Zeanah et al., 2009), and that characteristics of orphanages should be considered as an environmental factor influencing developmental difficulties in children living in institutions and later in post-institutional families.

This study aimed to analyze the structural characteristics of the caregiving environment in two St. Petersburg (RF) orphanages for infants and young children (baby homes). Since both of them belong to the Ministry of Health and are managed under the same medical regulations, they are assumed to have the same quality of medical care and nutrition for children. We hypothesized that although both baby homes belong to the same system of institutions, they will be different in their structural characteristics, namely in the stability and consistency of the institutional environment. 
The study results show that wards in $\mathrm{BH} \mathrm{A}$, in comparison with wards in $\mathrm{BH} \mathrm{B}$, have fewer staff members who are assigned to the ward (6-8 vs. 9-14), including during the day (3 vs.4). The ward assistant teachers in BH A are assigned as the primary caregivers, working 5 days a week for 39 hrs a week (vs. about 25 hrs a week for $\mathrm{AT}$ in $\mathrm{BH} \mathrm{B}$ ); wards in $\mathrm{BH} \mathrm{A}$ were integrated by age and disability (vs. segregation by age and partial disability integration in $\mathrm{BH} \mathrm{B}$ ); and there are virtually no transitions of children from one ward to another in BH A (vs. many transitions in $\mathrm{BH}$ B). While living in the baby home, children in $\mathrm{BH}$ A are assigned to only one ward (meaning the same caregivers, peers, rooms, etc.), while in $\mathrm{BH}$ B the children change their living ward when they reach a certain age or developmental milestone (on average 2.7 wards for the total group of children from BH B). During the observation period, the group of typically developing children from $\mathrm{BH}$ A experienced fewer transitions and changes in the caregiving environment (including transitions from the group to the isolation ward, to a children's hospital and back) than those from $\mathrm{BH}$ B.

The results support the hypothesis that the structural characteristics of the institutional environment in the two baby homes are different, and that in comparison with $\mathrm{BH} \mathrm{B}$, the structural characteristics of $\mathrm{BH}$ A show more stability and consistency. The interventions implemented in BH A by the St. Petersburg-USA Orphanage Research Project (reduction in group size, assignment of permanent primary caregivers to each group, age and disability integration of children, and no transitions of children to new wards; see The St. Petersburg-USA Orphanage Research Team, 2008) were maintained for many years after the project was finished. The second baby home (BH B), which offers the same quality of medical care and nutrition for children as $\mathrm{BH} \mathrm{A}$, but at which no intervention was provided, could be described as a "social-emotionally depriving institution" (Julian, 2013; Merz \& McCall, 2010), where children experienced low stability and consistency of the caregiving environment, and caregivers do not provide children the opportunity to interact and form attachment relationships.

During the period of observations in the two baby homes, the number of children in each was about the same, and the range of group sizes was similar, yet the caregiving stability and consistency were better for children in $\mathrm{BH} \mathrm{A}$. The daytime child-caregiver ratios in the wards of both baby homes were within about the same range (from 2.5 to 4 in $\mathrm{BH} \mathrm{B}$, and 2 to 3 in $\mathrm{BH} \mathrm{A}$ ), and indeed could promote developmental benefits for children, since the literature relates smaller group size to quality of care (NICHD Early Child Care Research Network, 2000), yet without stable and consistent caregivers, even the high caregiver-child ratio does not guarantee the adequate behavioral development of the children (Bamba \& Haight, 2007).

In recent years, the state policy of the Russian Federation on caring for children without parental care has been largely directed at keeping children in their birth families, placing children in different types of substitute families, and improving the quality of care in institutions for children who reside there. New regulations on improving institutions (Resolution of the Government of the RF No. 481, May 24, 2014, Moscow) were influenced by the intervention project in the St. Petersburg baby homes. The new policies require that living conditions in institutions should 
be close to several aspects of the family environment in the intervention. Specifically, group size should not exceed 6 for children up to 4 years and 8 for children over 4 years; groups should consist of children of different ages and disability status; the number of caregivers per group should be limited; and children should not be routinely transferred to new groups. Results of the study show that changes in institutional structure are needed in order to improve the caregiving environment for children who still live there.

\section{Conclusion}

Although the baby homes of St. Petersburg (and the Russian Federation) are similar in number, age range, and the disability status of children, as well as in the number and structure of personnel, there may be substantial differences in the characteristics of their caregiving environments. Studies of the structure and quality of institutional environments suggest that the roots of developmental delays often seen in children with institutional experience are seeded in the quality of their early environments. Thus, improving these caregiving environments could encourage children's better mental and physical well-being. The specificity of the institutional environment should be taken into consideration in studies of the mental health and bio-behavioral development of children in institutions and post-institutional families.

\section{Acknowledgments}

This study was supported by the Government of the Russian Federation (grant No. 14.Z50.31.0027). We are grateful to the directors of the baby homes, Dr. Natalia V. Nikiforova and Dr. Lubov M. Lyanko, for their extensive cooperation and support of the study, and to Elena V. Borisova for her administrative assistance.

\section{References}

Bakermans-Kranenburg, M. J., Bunkers, K. M., Dobrova-Krol, N. A., Engle, P., Fox, N. A., Gamer, G., ... Zeanah, C. H. (2012). The development and care of institutionally-reared children. Child Development Perspectives, 6 (2), 174-180. doi: 10.1111/j.1750-8606.2011.00231.x

Bamba, S., \& Haight, W. L. (2007). Helping maltreated children to find their Ibasho: Japanese perspectives on supporting the well-being of children in state care. Children and Youth Service Review, 29, 405-427. doi: 10.1016/j.childyouth.2006.10.001

Groark, C. J., McCall, R. B., McCarthy, S.K., Eichner, J.C., \& Gee, A.D. (2013). Structure, caregiver-child interactions, and children's general physical and behavioral development in three central American institutions. International Perspectives in Psychology: Research, Practice, Consultation, 2(3), 207-224. doi: 10.1037/ipp0000007

Gunnar, M. R. (2001). Effects of early deprivation: Findings from orphanage-reared infants and children. In C. A. Nelson \& M. Luciana (Eds.), Handbook of developmental cognitive neuroscience (pp. 619-629). Cambridge, MA: MIT Press.

McCall, R. B., van IJzendoorn, M. H., Juffer, F., Groark, C. J., \& Groza, V. K. (2011). Children without permanent parents: Research, practice, and policy. Monographs of the Society for Research in Child Development, 76(4), 1-318. doi: 10.1111/j.1540-5834.2011.00634.x 
Merz, E., \& McCall, R. B. (2010). Behavior problems in children adopted from psychosociallydepriving institutions. Journal of Abnormal Child Psychology, 38(4), 459-470. doi: 10.1007/ s10802-009-9383-4

Muhamedrahimov, R. J. (2000). New attitudes: Infant care facilities in St. Petersburg, Russia. In J. D. Osofsky \& H. E. Fitzgerald (Eds.), WAIMH handbook of infant mental health (Vol. 1, Perspectives on infant mental health) (pp. 245-294). New York, NY: Wiley.

Muhamedrahimov, R. J., Palmov, O. I., Nikiforova, N. V., Groark, C. J., \& McCall, R. B. (2004). Institution-based early intervention program. Infant Mental Health Journal, 25(5), 488-501. doi: 10.1002/imhj.20021

Nelson, C. A., Bos, K., Gunnar, M. R., \& Sonuga-Barke, E. J. S. (2011). The neurobiological toll of early human deprivation. In R. B. McCall, M. H. van IJzendoorn, F. Juffer, C. J. Groark, \& V. K. Groza (Eds.), Children without permanent parents: Research, practice, and policy. Monographs of the Society for Research in Child Development, 76(4), 127-146. doi: 10.1111/ j.1540-5834.2011.00630.x

NICHD Early Child Care Research Network (2000). Characteristics and quality of child care for toddlers and preschoolers. Applied Developmental Science, 4, 116-135. doi: 10.1207/ S1532480XADS0403_2

Rutter, M., Sonuga-Barke, E. J. S., Beckett, C., Castle, J., Kreppner, J., Kumsta, R., . . Bell, C. A. (2010). Deprivation-specific psychological patterns: Effects of institutional deprivation. Monographs of the Society for Research in Child Development, Serial No. 295, 75(1).

The St. Petersburg-USA Orphanage Research Team (2008).The effects of early social-emotional and relationship experience on the development of young children. Monographs of the Society for Research in Child Development, Serial No. 291, Vol. 72, No. 3.

Van IJzendoorn, M. H., Palacios, J., Sonuga-Barke, E. J. S., Gunnar, M. R., Vorria.P., McCall, R. B., ... Juffer, F. (2011). Children in institutional care: Delayed development and resilience. In R. B. McCall, M. H. van IJzendoorn, F. Juffer, C. J. Groark, \& V. K. Groza (Eds.), Children without permanent parents: Research, practice, and policy. Monographs of the Society for Research in Child Development, 76(4), 8-30. doi:10.1111/j.1540-5834.2011.00626.x

Vorria, P., Papaligoura, Z., Dunn, J., Van IJzendoorn, M. H., Steele, H., Kontopoulou, A., \& Sarafidou, Y. (2003). Early experiences and attachment relationships of Greek infants raised in residential group care. Journal of Child Psychology and Psychiatry, 44, 1208-1220. doi: 10.1111/1469-7610.00202

Zeanah, C.H., Egger, H.L., Smyke, A.T., Nelson, S.A., Fox, N.A., Marshall, P.J., \& Guthrie, D. (2009). Institutional rearing and psychiatric disorders in Romanian preschool children. American Journal of Psychiatry, 166(7), 777-785. doi: 10.1176/appi.ajp.2009.08091438.

Original manuscript received September 28, 2015

Revised manuscript accepted May 25, 2016

First published online September 30, 2016 